\title{
Identification of a gene, FMP21, whose expression levels are involved in thermotolerance in Saccharomyces cerevisiae
}

\author{
Toshihide Nakamura $^{1 *+}$, Mami Yamamoto ${ }^{1 \dagger}$, Katsuichi Saito ${ }^{1}$, Akira Ando $^{2}$ and Jun Shima ${ }^{3}$
}

\begin{abstract}
Elucidation of the mechanism of high temperature tolerance in yeasts is important for the molecular breeding of high temperature-tolerant yeasts that can be used in bioethanol production. We identified genes whose expression is correlated with the degree of thermotolerance in Saccharomyces cerevisiae by DNA microarray analysis. Gene expression profiles of three $S$. cerevisiae strains showing different levels of thermotolerance were compared, and we chose three of them as candidate genes. Among these genes, FMP21 was investigated as a thermotolerance-related gene in S. cerevisiae by comparing the growth at high temperature with the gene expression in eight strains. The expression ratio of FMP21 at $37^{\circ} \mathrm{C}$ was correlated with the doubling time ratio at a coefficient of determination of 0.787 . The potential involvement of the Fmp21 in the thermotolerance of yeasts was evaluated. The FMP21 deletion variant showed a decreased respiratory growth rate and increased thermosensitivity. Furthermore, the overexpression of FMP21 improved thermotolerance in yeasts. In conclusion, the function of Fmp21 is important for thermotolerance in yeasts.
\end{abstract}

Keywords: Thermotolerance; Yeast; Gene expression; Growth rate; FMP21

\section{Introduction}

The yeast Saccharomyces cerevisiae has been used in the production of traditional fermented foods and beverages as well as in the industrial production of ethanol. In the process of ethanol production, the temperature of the fermentor is raised by the heat of the fermentation, and the elevated temperature results in decreases in the cell growth, viability, and ethanol productivity of the yeast. Thermotolerant yeast is thus required for efficient ethanol production. The growth properties of S. cerevisiae at high temperatures differ according to the strain used, but the optimum temperature of proliferation is around $30^{\circ} \mathrm{C}$. Some high-temperature-resistant strains have been isolated from tropical areas and obtained by mutational improvement, breeding, or the cell fusion of existing strains (Pasha et al. 2007; Marullo et al. 2009; Shi et al. 2009). These thermotolerant yeasts were selected based on the cell growth and ethanol production at high temperature.

\footnotetext{
* Correspondence: nakamrto@affrc.go.jp

${ }^{\dagger}$ Equal contributors

${ }^{1}$ National Food Research Institute, National Agriculture and Food Research Organization (NARO), 2-1-12 Kannondai, Tsukuba, Ibaraki 305-8642, Japan Full list of author information is available at the end of the article
}

Analyses of genes whose expression is induced by high temperature are important for understanding the mechanisms of thermotolerance, and for the use of the genes in breeding thermotolerant yeasts. Genes related to the thermotolerance of S. cerevisiae have been identified by DNA microarray analyses (Eisen et al. 1998; Sakaki et al. 2003) and a genome-wide screening of an S. cerevisiae deletion mutant collection (Auesukaree et al. 2009). Many genes were found to be important for the tolerance to heat stress (Auesukaree et al. 2009).

Genomic regions related to the high-temperature growth of $S$. cerevisiae were identified by quantitative trait locus (QTL) mapping (Steinmetz et al. 2000; Sinha et al. 2006, 2008). The QTL map contained MKT1, END3, and RHO2 as high-temperature growth quantitative trait genes. Other factors such as heat shock proteins and trehalose also function in yeast as protectants contributing to survival under heat stress conditions (Watson 1990; Singer and Lindquist 1998). However, the mechanisms of thermotolerance in yeasts are still unclear.

In the present study, we attempted to identify genes whose expression is correlated with the degree of thermotolerance in $S$. cerevisiae. We compared the gene 
expression profiles of three $S$. cerevisiae strains that showed different levels of thermotolerance. We investigated FMP21 as a thermotolerance-related gene in S. cerevisiae by comparing the growth at high temperature with the gene expression in eight strains.

\section{Materials and methods Yeast strains and growth conditions}

The yeasts used in this study (Saccharomyces cerevisiae NFRI 3122, NFRI 3145, NFRI 3155, NFRI 3205, NFRI 3225, NFRI 3236, and NFRI 3314) were obtained from the Microbiological Bank at our institute (NFRI). Saccharomyces cerevisiae S288C was used as a control strain. A wild-type strain, S. cerevisiae BY4743 and the deletion strain fmp21 $1 \Delta$ derived from BY4743 were obtained from EUROSCARF (EUROpean Saccharomyces Cerevisiae ARchive for Functional analysis). The strains were grown in YPD medium (1\% yeast extract [Difco Laboratory, Detroit, MI, USA], 2\% peptone [Difco Laboratory], and $2 \%$ glucose) with shaking at $140 \mathrm{rpm}$.

\section{Determination of growth rates}

The yeast strains were inoculated into YPD medium and incubated at $30^{\circ} \mathrm{C}$ for $24 \mathrm{~h}$ (pre-culture). Cell growth was monitored by measuring the optical density of the cultures at $600 \mathrm{~nm}\left(\mathrm{OD}_{600}\right)$ using a spectrophotometer (Ultrospec 2100 pro; GE Healthcare, Freiburg, Germany). The cells were transferred to YPD medium at a starting $\mathrm{OD}_{600}$ of 0.1 and incubated at $30^{\circ} \mathrm{C}$ with shaking. The experiments were performed in triplicate. Growth rates, expressed as the time required for the cultures to double in optical density (doubling time, $T_{\mathrm{d}}$ ), were calculated by comparing the optical density at multiple time points during the linear growth phase and using the following formula:

$$
T_{\mathrm{d}}=\left(t_{2}-t_{1}\right) /\left[\log _{2}\left(\mathrm{OD}_{2} / \mathrm{OD}_{1}\right)\right]
$$

\section{Heat treatment for total RNA extraction}

To confirm the heat tolerance of the strains, the cells were cultured in YPD medium under high-temperature conditions. Yeast cells were inoculated at an initial cell density of 0.1 at $\mathrm{OD}_{600}$ and grown to $1.0 \mathrm{OD}_{600}$. Aliquots $(10 \mathrm{~mL})$ of exponentially growing cells were transferred to preheated conical flasks of replicates of each strain. The flasks were placed in a $37^{\circ} \mathrm{C}$ or $39^{\circ} \mathrm{C}$ water bath for $30 \mathrm{~min}$.

\section{DNA microarray analysis}

The experimental procedures used for the RNA extraction and DNA microarray analysis have been described previously (Nakamura et al. 2008). The total RNA was quantified using a Bioanalyzer 2100 with an RNA 6000 Nano LabChip kit (Agilent Technologies, Palo Alto, CA, USA). Polyadenylated RNA (mRNA) from total RNA was purified using Oligotex-dT30 $<$ Super $>$ (Takara, Kyoto, Japan) according to the manufacturer's instructions. We performed complementary DNA synthesis and labeling and array hybridization by following the Affymetrix user's manual with a one-cycle target labeling and control reagent kit (Affymetrix, Santa Clara, CA, USA) with $0.4 \mu \mathrm{g}$ of mRNA as the template material. Labeled cDNA was hybridized to Affymetrix GeneChip Yeast 2.0 arrays (Affymetrix) for $16 \mathrm{~h}$ at $45^{\circ} \mathrm{C}$ with constant rotation at $60 \mathrm{rpm}$. Washing and staining were performed using a hybridization, wash, and stain kit (Affymetrix) on a GeneChip FS-450 fluidics station (Affymetrix). Fluorescence was detected using the Affymetrix 3000 GeneArray Scanner, and the image analysis of each GeneChip was performed using the GeneChip Operating System 1.4.0 (GCOS) software from Affymetrix with the standard default settings. Probe level data based on the gene expression data from two independent experiments were imported into GeneSpring GX 11.0.2 (Agilent Technologies). Following 75th percentile shift normalization, lowintensity probes subject to high degrees of noise were removed by filtering the lowest $20 \%$ of each sample and then by filtering with flags (present and marginal). For the identification of differentially expressed genes, the Filter on Confidence function was used with a $t$-test $P$-value cutoff of 0.05 , and a fold change threshold of 1.0 for the gene list was generated using the Filter on Volcano Plot tool. All experiments were done in duplicate with independently grown cells.

Microarray data from the present study have been deposited in the Gene Expression Omnibus (GEO) repository at the National Center for Biotechnology Information (NCBI) under series accession no. GSE33276.

\section{PCR primers and real-time RT-PCR}

The oligonucleotide primer pairs listed in Table 1 were designed using Primer3 (http://primer3.sourceforge.net/). Real-time reverse transcription polymerase chain reaction (RT-PCR) was carried out using the LightCycler 2.0 instrument in glass capillaries (Roche, Indianapolis, IN, USA). Two $\mu \mathrm{g}$ of total RNA was reverse-transcribed into cDNA in a $20-\mu \mathrm{L}$ reaction mixture using a PrimeScript Reverse Transcriptase kit (Takara). The reaction mix consisted of $5 \mu \mathrm{L}$ standard/diluted cDNA template $(1 / 10$ to $1 / 1000$ ), $0.5 \mu \mathrm{L} 10 \times$ primer for the gene [final $0.5 \mu \mathrm{M}$ primer, and $2.5-4 \mathrm{mM} \mathrm{MgCl} 2], 2 \mu \mathrm{L}$ water, and $2 \mu \mathrm{L}$ FAST-START DNA Master SYBR Green I mix (Roche). The reaction conditions were as follows: initial denaturation at $95^{\circ} \mathrm{C}$ for $10 \mathrm{~min}$, followed by 38 cycles of denaturation at $95^{\circ} \mathrm{C}$ for $10 \mathrm{~s}$, annealing at $60^{\circ} \mathrm{C}$ for $10 \mathrm{~s}$, and extension at $72^{\circ} \mathrm{C}$ for $10 \mathrm{~s}$. The progress of real-time fluorescent PCR was monitored at $530 \mathrm{~nm}$.

The PCR products were verified with both a melting curve analysis and DNA gel electrophoresis. To establish 
Table 1 List of primers used in this study

\begin{tabular}{|c|c|c|}
\hline Primer & Nucleotide sequence $\left(5^{\prime}-3^{\prime}\right)$ & Target ORF \\
\hline \multicolumn{3}{|c|}{ Real-time PCR experiments } \\
\hline YER034W-F & CACCCAGTGATAGAAAGTACCG & YER034W \\
\hline YER034W-R & TCCTCATAGTACCTGTCCTCG & YER034W \\
\hline prm5-F & GCAATTITTGCGGGTTTCCTTA & PRM5 (YIL117C) \\
\hline prm5-R & TCGTCGCTCGATAACGGTA & PRM5 (YIL117C) \\
\hline YBR269C-F & TCGCAAGAGGCAATAGATCAG & FMP21 (YBR269C) \\
\hline YBR269C-R & TCGAATTCAGGTATGGTCTTGG & FMP21 (YBR269C) \\
\hline Act1-F & AGCCTTCTACGTTTCCATCC & $A C T 1$ \\
\hline Act1-R & CTITCAGCAGTGGTGGAGAA & $A C T 1$ \\
\hline \multicolumn{3}{|c|}{ Construction of the FMP21-overexpressing strain } \\
\hline URA3-F & CAGGGTCCATAAAGCTIT & \\
\hline URA3-R & TITATAAAGGCCATGAAGCT & \\
\hline TDH3 pro-F & GGAAAGAAAAAGCTTCATGGCCTTTATAAAAACACGCTTITCAGTTC & \\
\hline TDH3 pro-R & TTGTTGTTTATGTGTGTT & \\
\hline FMP21-A & AACGCACTCAAGGTITTGG & \\
\hline FMP21-B & AAGATGAATTGAAAAGCTTTATGGACCCTGTAGTTCTTCTTTTATTATT & \\
\hline FMP21-C & GTTTCGAATAAACACACATAAACAAACAAAATGTTGTGCGCCATCAAAAG & \\
\hline FMP21-D & GTATGAATGTGCCCAGTGTA & \\
\hline
\end{tabular}

the external standard curves for the quantification of each gene, the purified PCR products were diluted in a 10 -fold series (1/10 to $1 / 10000)$ and analyzed with the new assay. The expression data and associated technical errors on duplicates were calculated by using LightCycler Software 4.0 (Roche). The expression levels for each sample were normalized for the expression of ACT1.

The gene expression rate is based on the expression levels of the target gene versus the reference gene (ACT1). We confirmed that the ACT1 expression was stable under high temperature conditions by comparing it with the expression of $A L G 9$, which is considered a suitable reference gene for real-time RT-PCR (Teste et al. 2009). The gene expression ratio is given as the ratio of the target gene expression rate after heat treatment to that in non-treated controls.

\section{Assay for thermotolerance}

Yeast strains were precultured in YPD medium until the $\log$ phase. Then, the preculture was inoculated into $5 \mathrm{ml}$ of YPD medium and shaken at $70 \mathrm{rpm}$ under aerobic conditions at $30^{\circ} \mathrm{C}$ or $39^{\circ} \mathrm{C}$. The $\mathrm{OD}_{660}$ was automatically recorded with an Advantec TVS062CA biophotorecorder (Advantec Toyo Co. Ltd., Tokyo, Japan).

\section{Construction of FMP21-overexpressing strains}

We constructed an FMP21-overexpressing strain based on a previously reported method (Hasegawa et al. 2012) using the primer set listed in Table 1. Briefly, the promoter region of the glyceraldehyde-3-phosphate dehydrogenase gene (TDH3), which allows constitutive expression at a high level, was fused with the URA3 marker gene and then inserted upstream of the start codon of the FMP21 gene in BY4743. The resultant FMP21-overexpressing strains (MATa/ $\alpha$ ura3 $\triangle O$ URA3$\left.P_{T D H 3}-F M P 21\right)$ and control strains (MATa/ $\alpha$ ura $3 \Delta 0$ URA3) were analyzed for FMP21 expression levels and thermotolerance. The expression levels of FMP21 were determined by real-time RT-PCR as described above.

\section{Results}

Screening of thermotolerance-related genes by DNA microarray analysis

We used three yeast strains: a thermotolerant strain, NFRI 3236; a thermosensitive strain, NFRI 3155; and a standard strain, S288C (Figure 1). The doubling times $\left(\mathrm{T}_{\mathrm{d}}\right)$ of NFRI 3236 , NFRI 3155 and $\mathrm{S} 288 \mathrm{C}$ at $39^{\circ} \mathrm{C}$ were shown to be $1.75,2.90$ and $2.11 \mathrm{~h}$, respectively. On the other hand, the $\mathrm{T}_{\mathrm{d}}$ values of NFRI 3236, NFRI 3155 and $\mathrm{S} 288 \mathrm{C}$ at $30^{\circ} \mathrm{C}$, a standard growth condition for the strains, showed no significant differences and were 1.15, 1.28 and $1.34 \mathrm{~h}$, respectively.

We performed DNA microarray experiments in order to compare gene expression responses to the heat treatment at $39^{\circ} \mathrm{C}$ with the gene expressions in non-treated control cells. We first selected genes (441 genes) that showed a higher than 1.5-fold change in their expression in both NFRI 3236 and S288C, and then selected genes that showed $\mathrm{a}>1.5$ ratio of fold-change values of NFRI 3236 to S288C or of S288C to NFRI 3155. We then 

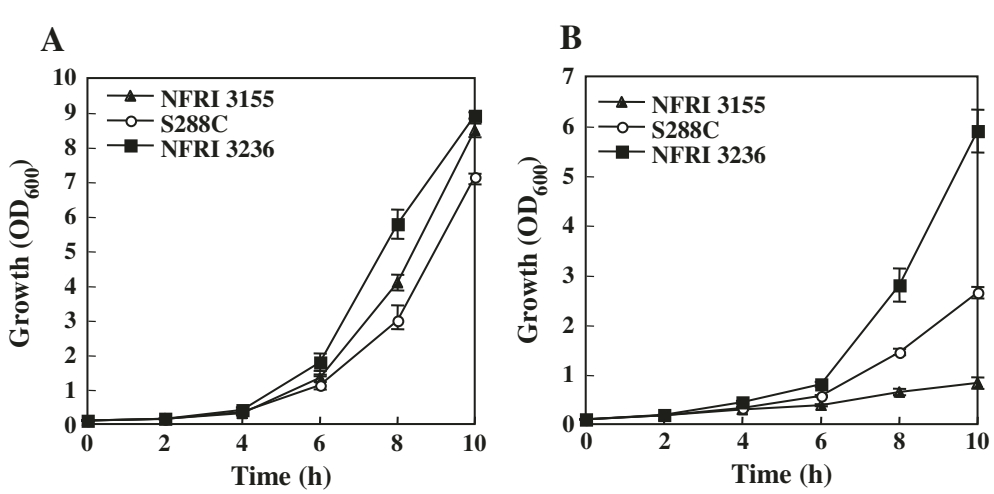

Figure 1 Effect of temperature on the growth of three yeast strains (NFRI 3236, NFRI 3155 and S288C). Each strain was grown in YPD with shaking at $30^{\circ} \mathrm{C}(\mathbf{A})$, or $39^{\circ} \mathrm{C}(\mathbf{B})$.

selected three genes whose expression ratios were correlated with the level of thermotolerance in the three strains (Table 2). The fold-change values of $Y E R 034 \mathrm{~W}$, YIL117C (PRM5) and YBR269C (FMP21) were more clearly correlated with the rank order of thermotolerance. We thus chose YER034W, PRM5 and FMP21 as candidate thermotolerance-related genes.

\section{Expression analysis of the three candidates by real-time RT-PCR}

We verified the expression of YER034W, PRM5 and FMP21 in NFRI 3236, NFRI 3155 and S288C under heat stress conditions. The expression ratio (i.e., the expression level at high temperature/the expression level at $30^{\circ}$ C) of each candidate gene was measured by real-time RT-PCR (Figure 2). The ACT1 gene was used as the expression standard. The expression ratio of FMP21 was 3.47 in NFRI 3155, 4.50 in S288C and 8.50 in NFRI 3236 , and it increased (statistically significant at $P<0.05$ ) according to the thermotolerance of the yeast strains. However, the expression ratios of YERO34W and PRM5 showed no relationship with the thermotolerance of the yeast strains.

\section{Relationship between the expression of FMP21 and the} thermotolerance of yeast strains

To assess the relationship between the expression of the FMP21 gene and the thermotolerance of yeast strains, we measured the expression levels at $30^{\circ} \mathrm{C}, 37^{\circ} \mathrm{C}$, and $39^{\circ} \mathrm{C}$ in five strains (NFRI 3122, NFRI 3145, NFRI 3205, NFRI 3225, and NFRI 3314) in addition to the three strains described above (eight strains total). Figure 3 is a graph plotting the expression ratios of FMP21 against the $\mathrm{T}_{\mathrm{d}}$ ratio. With the heat treatment of $37^{\circ} \mathrm{C}$, the increase of the expression ratio of FMP21 by heat treatment was correlated with the $\mathrm{T}_{\mathrm{d}}$ ratio at a coefficient of determination of 0.787 . In contrast, there was weak correlation at $39^{\circ} \mathrm{C}$ (coefficient of determination, 0.418).

\section{Disruption and overexpression of the FMP21 gene}

To determine whether Fmp21 plays a role in the response to heat stress, we examined the growth ability of the FMP21 deletion strain $(f m p 21 \Delta)$ in YPD medium at $39^{\circ} \mathrm{C}$ (Figure 4 ). The growth ability of fmp $21 \Delta$ in YPD medium at $30^{\circ} \mathrm{C}$ was nearly the same as that of the wildtype strain; however, there was a reduction in the growth rate of $f m p 21 \Delta$ in the late growth phase. Under the high temperature condition, fmp $21 \Delta$ showed a slower growth rate than the wild-type strain in the log-phase. This result revealed that the deletion of FMP21 increased the sensitivity to high temperature.

To evaluate the phenotype of FMP21 overexpression, we constructed FMP21-overexpressing strains and compared their thermotolerance with that of the control strains. FMP21 was overexpressed using promoter sequences of the highly expressed TDH3 gene. Then we

Table 2 Selected genes and their expression values in DNA microarray analysis

\begin{tabular}{|c|c|c|c|c|}
\hline \multirow[t]{2}{*}{ Gene } & \multicolumn{3}{|c|}{ Fold change } & \multirow[t]{2}{*}{ Descriptions of gene products } \\
\hline & NFRI3236 & S288C & NFRI3155 & \\
\hline FMP21 & 3.68 & 2.18 & 1.35 & $\begin{array}{l}\text { Putative protein of unknown function; the authentic, non-tagged protein is detected in highly purified } \\
\text { mitochondria in high-throughput studies }\end{array}$ \\
\hline YER034W & 3.10 & 1.51 & 0.49 & Putative protein of unknown function; non-essential gene; expression induced upon calcium shortage \\
\hline PRM5 & 48.21 & 23.05 & 15.07 & $\begin{array}{l}\text { Pheromone-regulated protein, predicted to have } 1 \text { transmembrane segment; induced during cell integrity } \\
\text { signaling }\end{array}$ \\
\hline
\end{tabular}



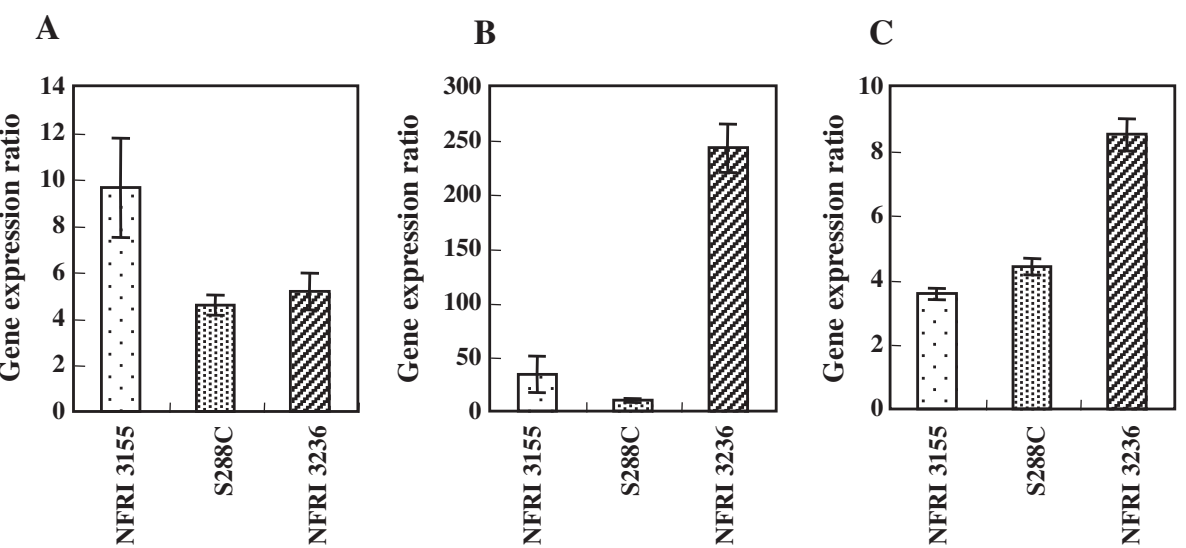

Figure 2 Comparison of the gene expression ratios of the selected genes. (A) YERO34W, (B) PRM5, and (C) FMP21. Bars indicate the mean ratios for two independent biological replicates. Error bars = standard deviation.

confirmed the mRNA expression of FMP21 by real-time RT-PCR (Figure 5). In the FMP21-overexpressing strains (BY4743/PTDH3-FMP21), the transcriptional expression level of FMP21 was approximately 6-fold higher under non-stress conditions and was approximately 3-fold higher at $39^{\circ} \mathrm{C}$ (the differences are statistically significant at $P<0.01$ ). Overexpression of $F M P 21$ had no effect on the growth rate at $30^{\circ} \mathrm{C}$ (Figure 6). The growth rate of FMP21-overexpressing strains was higher than that of the control strains when the cells were incubated at $39^{\circ} \mathrm{C}$ (Figure 6). These results suggested that yeast strains with enhanced FMP21 expression exhibited the improved thermotolerance.

\section{Discussion}

We found a correlative increase of FMP21 expression along with the increase in growth rate at high temperature in yeast strains. The results of our DNA microarray analysis using three strains showed increased expression ratios under heat conditions for FMP21, YER034W and PRM5. However, in the verification test, the expression rate of YERO34W showed the lowest correlation among the three genes. In addition, the expression rate of PRM5 was significantly increased by heat treatment only in the NFRI3236 strain. The expression levels in some of the genes were very different among the yeast strains, which had different genetic backgrounds. PRM5 is also one of the genes whose expression strongly depends on the genetic backgrounds of the strains.

The expression ratio of FMP21 induced by heat treatment was significantly correlated with the growth ratio at $37^{\circ} \mathrm{C}$. However, there was a weak correlation at $39^{\circ} \mathrm{C}$. Generally, $S$. cerevisiae strains show various levels of thermotolerance depending on their genetic backgrounds. The maximum temperature for growth is under about $40^{\circ} \mathrm{C}$. The strains used in this study grew unstable at $39^{\circ} \mathrm{C}$, and there is therefore a high possibility that the gene expressions at $39^{\circ} \mathrm{C}$ would also be unstable. Therefore, we
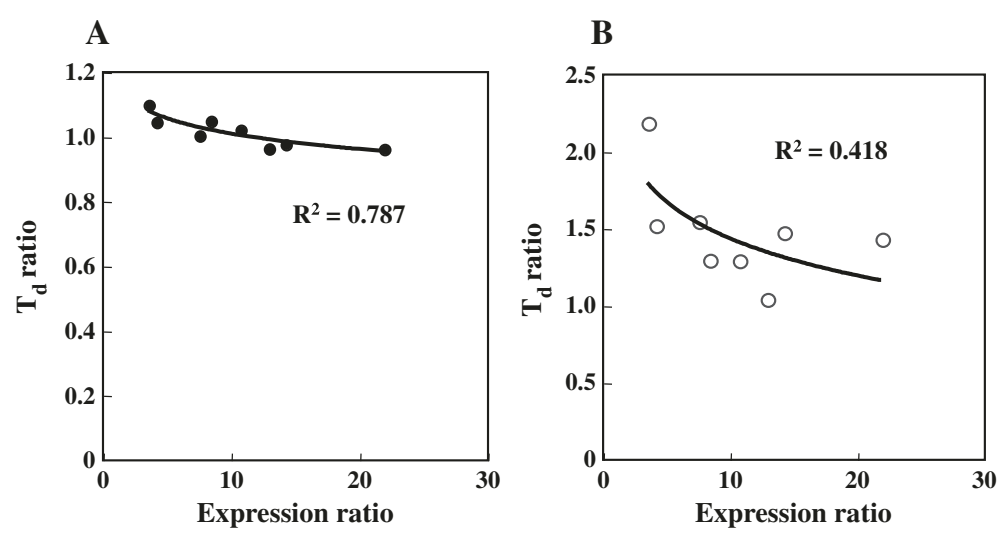

Figure 3 Relationship between the expression ratio of $F M P 21$ and the doubling time $\left(\mathrm{T}_{\mathrm{d}}\right)$ ratio at $37^{\circ} \mathrm{C}\left(30^{\circ} \mathrm{C} / 37^{\circ} \mathrm{C}\right)(\mathrm{A})$ and at $39^{\circ} \mathrm{C}$ $\left(30^{\circ} \mathrm{C} / 39^{\circ} \mathrm{C}\right)(\mathbf{B})$. The coefficients of determination $\left(R^{2}\right)$ were $0.787(\mathbf{A})$ and 0.418 (B). 


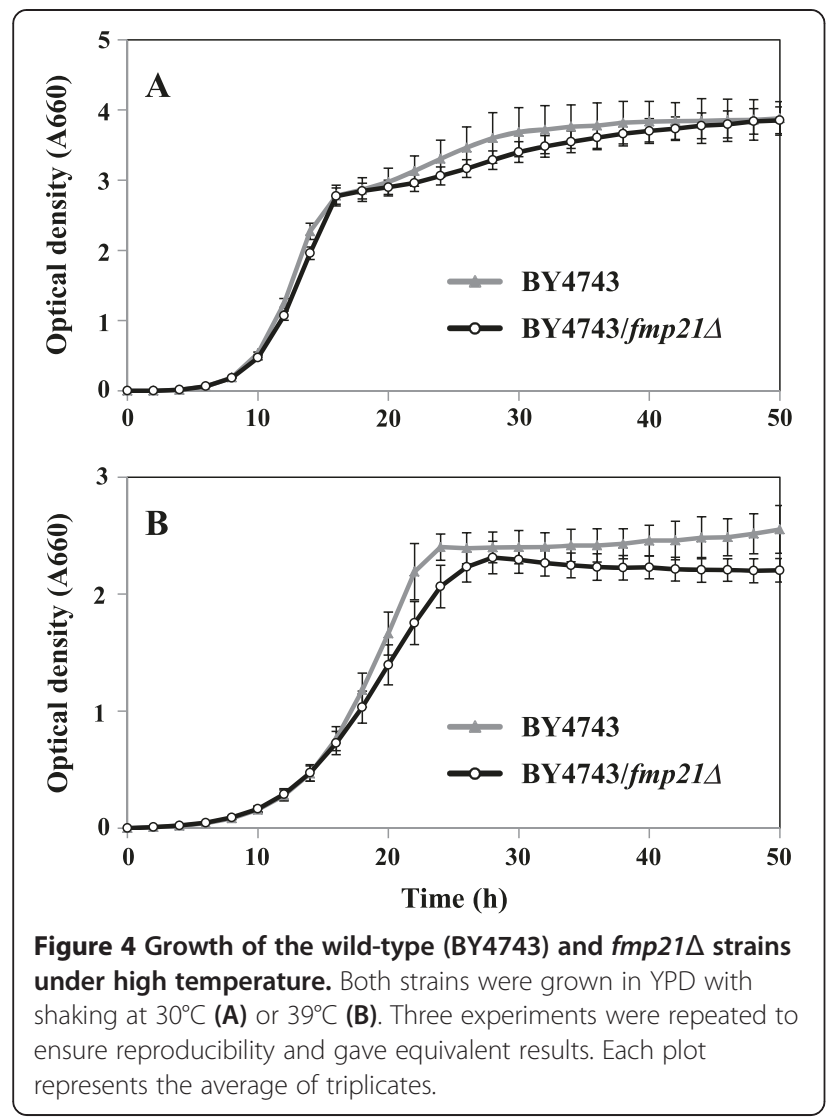

speculated that the unstable gene expressions at $39^{\circ} \mathrm{C}$ may have been responsible for the relatively low value of the coefficient of determination.

In yeasts, Hsf1 and Msn2/4 are major transcription factors to respond to heat stress. Hsf1 and Msn2/4 bind to heat shock elements (HSEs) and stress response elements (STREs), respectively, in the promoter region of

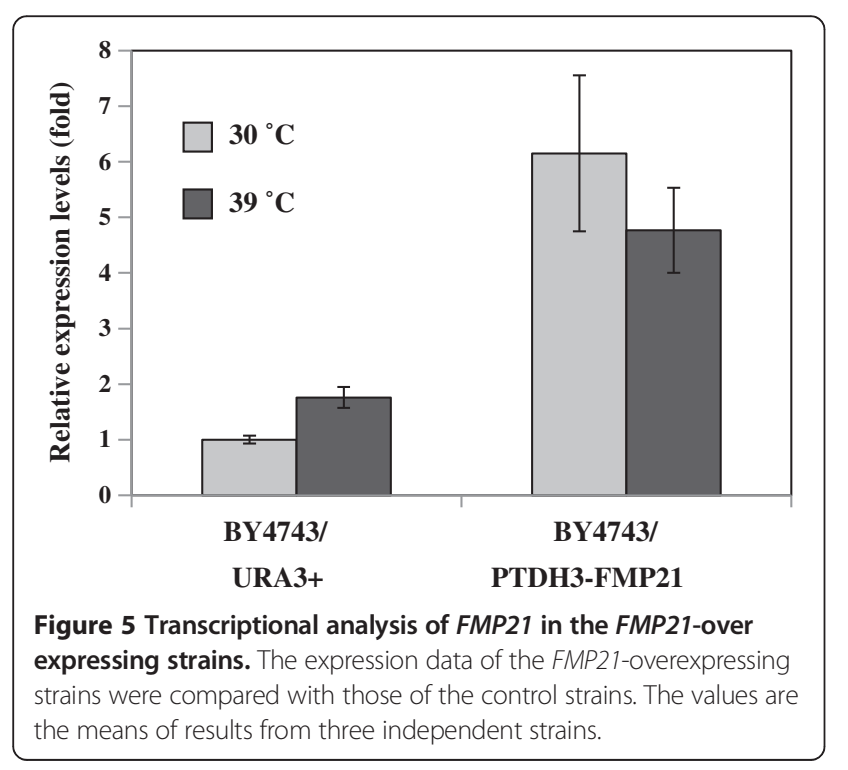

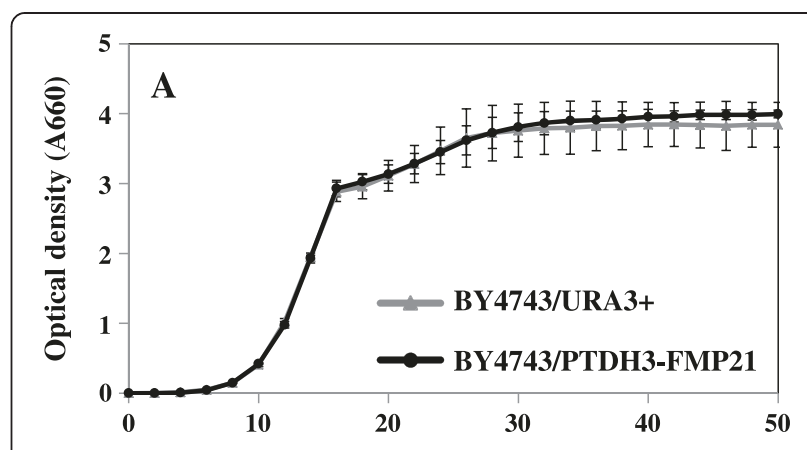

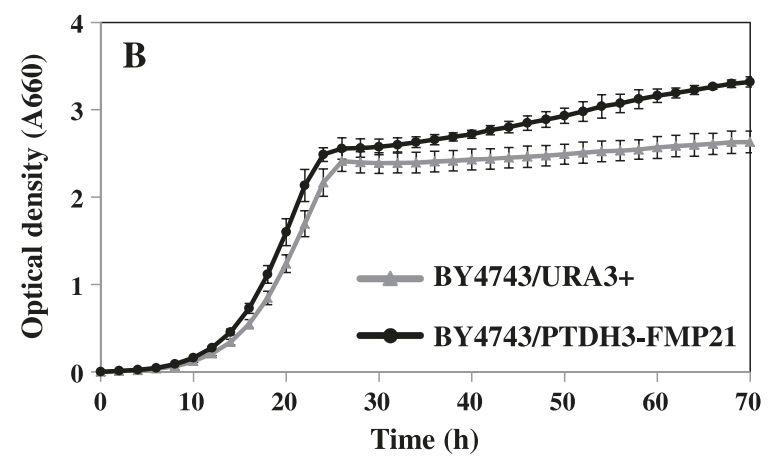

Figure 6 Growth of the FMP21-overexpressing strains under high temperature. Both the FMP21-overexpressing strains and the control strains were grown in YPD with shaking at $30^{\circ} \mathrm{C}$ (A) or $39^{\circ} \mathrm{C}$ (B). The values are the means of results from three independent strains.

heat shock proteins and activate the expression of target gene transcription (Morano et al. 2012). Although the expression of FMP21 was induced by heat stress, we did not find the typical consensus sequences of HSEs and STREs in the promoter region of FMP21. The FMP21 expression may be controlled by unknown mechanisms. In contrast to the expression pattern of FMP21, Sakaki et al. (2003) reported that the expressions of mitochondrial genes were repressed in yeast cells grown at $37^{\circ} \mathrm{C}$. We are interested in the functions of Fmp21-specifically whether this protein is involved in the repression of mitochondrial genes in $37^{\circ} \mathrm{C}$ cultivation.

FMP21 encodes a protein localized in mitochondria, but its function is still unknown (Reinders et al. 2006). Steinmetz et al. (2002) reported that the FMP21 deletion variant showed a decreased rate of respiratory growth. We also confirmed that the fmp21D strains showed a decreased growth rate in medium containing glycerol as a sole carbon source (data not shown). The fmp21A strains showed a decreased growth rate after diauxic shift, suggesting that one of the functions of Fmp21 is to contribute to the respiratory metabolism in mitochondria of yeasts. After diauxic shift, yeasts are stressed by the lack of nutrients and by the accumulation of toxic metabolites such as ethanol. Outten et al. (2005) reported that the FMP21 deletion variant was hyperoxia- 
sensitive. The absence of Fmp21 may render the mitochondrial function more stress-sensitive.

The FMP21 deletion variant was a thermosensitive strain. As growth delay was observed in the late log phase, fmp21ム strains might be sensitive to ethanol under high temperature conditions. However, the sensitivity to $5 \%$ $(\mathrm{v} / \mathrm{v})$ ethanol of $f m p 21 \Delta$ strains was similar to that of the wild-type strain at $30^{\circ} \mathrm{C}$ (data not shown). Thus it is unlikely that a function of Fmp21 is involved in ethanol tolerance. We therefore consider that the function of Fmp21 is important for the thermotolerance of yeasts.

The increased accumulation of thermoprotectants in yeasts occasionally leads to increased thermotolerance. The overexpression of heat shock proteins and the enzyme for trehalose synthesis have been shown to successfully enhance the thermotolerance of yeasts (Cheng et al. 1992; An et al. 2011). In this study, the FMP21 gene was overexpressed using the promoter region of the TDH3 gene. Although the expression of TDH3 was decreased under high temperature (based on the DNA microarray analysis data), the expression of FMP21 in the FMP21-overexpressing strains was higher than that in the control strains. The overexpression of the FMP21 gene enhanced the thermotolerance of yeasts in aerobic cultures. As the overexpression of the FMP21 gene also enhanced the growth in static cultures under high temperature conditions, there was no significant difference in ethanol productivity (data not shown). These results suggest that Fmp21 contributes to thermotolerance of yeasts, and that it may protect mitochondria against high temperature-related damages.

Thermotolerant yeast strains are still required in bioindustries. Various approaches have been adopted in an attempt to improve the thermotolerance of yeast strains, including the use of mating, fusion or genetic hybridization (Pasha et al. 2007; Marullo et al. 2009; Shi et al. 2009). However, these approaches were based on stochasticity and used various yeast strains with different genetic backgrounds. It is thus difficult to draw conclusions from these studies that would help in the acquisition of more thermotolerant strains. The results presented here are applicable to various strains that have different genetic backgrounds. It may also be possible to use these results to quantify and evaluate thermotolerance, and for the systematic construction of more thermotolerant strains.

\section{Competing interests}

The authors declare that they have no competing interests.

\section{Acknowledgements}

This work was partly supported by a grant from the Ministry of Agriculture, Forestry and Fisheries of Japan (Rural Biomass Research Project, BEC-BC050, BEC-BC051), and Advanced Low Carbon Technology Research and Development Program of Japan (ALCA) of Japan Science and Technology Agency (JST).

\section{Author details}

${ }^{1}$ National Food Research Institute, National Agriculture and Food Research Organization (NARO), 2-1-12 Kannondai, Tsukuba, Ibaraki 305-8642, Japan. ${ }^{2}$ NARO Institute of Vegetable and Tea Science, 360 Kusawa, Ano, Tsu, Mie 514-2392, Japan. ${ }^{3}$ Ryukoku University, Fukakusa Tsukamotohon-cho, Fushimi-ku, Kyoto, Kyoto 612-8577, Japan.

Received: 4 August 2014 Accepted: 9 August 2014

Published online: 23 August 2014

\section{References}

An MZ, Tang YQ, Mitsumasu K, Liu ZS, Shigeru M, Kenji K (2011) Enhanced thermotolerance for ethanol fermentation of Saccharomyces cerevisiae strain by overexpression of the gene coding for trehalose-6-phosphate synthase. Biotechnol Lett 33:1367-1374, doi:10.1007/s10529-011-0576-x

Auesukaree C, Damnernsawad A, Kruatrachue M, Pokethitiyook P, Boonchird C, Kaneko Y, Harashima S (2009) Genome-wide identification of genes involved in tolerance to various environmental stresses in Saccharomyces cerevisiae. J Appl Genet 50:301-310, doi:10.1007/BF03195688

Cheng L, Hirst K, Piper PW (1992) Authentic temperature-regulation of a heat shock gene inserted into yeast on a high copy number vector. Influences of overexpression of HSP90 protein on high temperature growth and thermotolerance. Biochim Biophys Acta 1132:26-34, doi:10.1016/0167-4781(92) 90048-5

Eisen MB, Spellman PT, Brown PO, Botstein D (1998) Cluster analysis and display of genome-wide expression patterns. Proc Natl Acad Sci U S A 95:14863-14868, doi:10.1073/pnas.95.25.14863

Hasegawa S, Ogata T, Tanaka K, Ando A, Takagi H, Shima J (2012) Overexpression of vacuolar $\mathrm{H}^{+}$-ATPase-related genes in bottom-fermenting yeast enhances ethanol tolerance and fermentation rates during high-gravity fermentation. J Inst Brew 118:179-185, doi:10.1002/jib.32

Marullo P, Mansour C, Dufour M, Albertin W, Sicard D, Bely M, Dubourdieu D (2009) Genetic improvement of thermo-tolerance in wine Saccharomyces cerevisiae strains by a backcross approach. FEMS Yeast Res 9:1148-1160, doi:10.1111/j.1567-1364.2009.00550.x

Morano KA, Grant CM, Moye-Rowley WS (2012) The response to heat shock and oxidative stress in Saccharomyces cerevisiae. Genetics 190:1157-1195, doi:10.1534/genetics.111.128033

Nakamura T, Mizukami-Murata S, Ando A, Murata Y, Takagi H, Shima J (2008) Changes in gene expression of commercial baker's yeast during an air-drying process that simulates dried yeast production. J Biosci Bioeng 106:405-408, doi:10.1263/jbb.106.405

Outten CE, Falk RL, Culotta VC (2005) Cellular factors required for protection from hyperoxia toxicity in Saccharomyces cerevisiae. Biochem J 388:93-101, doi:10.1042/BJ20041914

Pasha C, Kuhad RC, Rao LV (2007) Strain improvement of thermotolerant Saccharomyces cerevisiae VS strain for better utilization of lignocellulosic substrates. J Appl Microbiol 103:1480-1489, doi:10.1111/j.13652672.2007.03375.x

Reinders J, Zahedi RP, Pfanner N, Meisinger C, Sickmann A (2006) Toward the complete yeast mitochondrial proteome: multidimensional separation techniques for mitochondrial proteomics. J Proteome Res 5:1543-1554, doi:10.1021/pr050477f

Sakaki K, Tashiro K, Kuhara S, Mihara K (2003) Response of genes associated with mitochondrial function to mild heat stress in yeast Saccharomyces cerevisiae. J Biochem 134:373-384, doi:10.1093/jb/mvg155

Shi DJ, Wang CL, Wang KM (2009) Genome shuffling to improve thermotolerance, ethanol tolerance and ethanol productivity of Saccharomyces cerevisiae. J Ind Microbiol Biotechnol 36:139-147, doi:10.1007/s10295-008-0481-z

Singer MA, Lindquist S (1998) Thermotolerance in Saccharomyces cerevisiae: the Yin and Yang of trehalose. Trends Biotechnol 16:460-468, doi:10.1016/S0167-7799(98)01251-7

Sinha H, Nicholson BP, Steinmetz LM, McCusker JH (2006) Complex genetic interactions in a quantitative trait locus. PLoS Genet 2:e13, doi:10.1371/journal.pgen.0020013

Sinha H, David L, Pascon RC, Clauder-Münster S, Krishnakumar S, Nguyen M, Shi G, Dean J, Davis RW, Oefner PJ, McCusker JH, Steinmetz LM (2008) Sequential elimination of major-effect contributors identifies additional quantitative trait loci conditioning high-temperature growth in yeast. Genetics 180:1661-1670, doi:10.1534/genetics.108.092932 
Steinmetz LM, Scharfe C, Deutschbauer AM, Mokranjac D, Herman ZS, Jones T,

Chu AM, Giaever G, Prokisch H, Oefner PJ, Davis RW (2002) Systematic screen for human disease genes in yeast. Nat Genet 31:400-404, doi:10.1038/ng929

Teste MA, Duquenne M, François JM, Parrou JL (2009) Validation of reference genes for quantitative expression analysis by real-time RT-PCR in

Saccharomyces cerevisiae. BMC Mol Biol 10:99, doi:10.1186/1471-2199-10-99

Watson K (1990) Microbial stress proteins. Adv Microb Physiol 31:183-223

doi:10.1186/s13568-014-0067-2

Cite this article as: Nakamura et al:: Identification of a gene, FMP21,

whose expression levels are involved in thermotolerance in

Saccharomyces cerevisiae. AMB Express 2014 4:67.

\section{Submit your manuscript to a SpringerOpen ${ }^{\circ}$ journal and benefit from:}

- Convenient online submission

$\checkmark$ Rigorous peer review

- Immediate publication on acceptance

- Open access: articles freely available online

- High visibility within the field

- Retaining the copyright to your article 